\title{
MAHABBAH DALAM TASAWUF RABÎ'AH AL-ADAWIYAH : Apresiasi atas Rintisan Mistik Sejati dalam Islam
}

\author{
Oleh: Ach. Maimun"
}

Abstract

This paper aims to discuss on Rabi'ah al-'Adawiyah's mahabbah teaching as the beginning pattern of Sufism. In the first century of Islam, the Sufism life or known as the spiritual life was based on fear (khauf) which then expanded beisome the resignation (tawakkal) to the God. In the second century, the meaning of mahabbah or called the divine love was raised and changed toward extreme pole. The figure who starting the change of mahabbah meaning from rational one to the emotional one was Rabi'ah al-Adawiyah. Mahabbah in Sufism discourse is the highest degree in Rabi'ah teaching. The value of pure love in Sufism life granted the big change toward of next path of Sufism. All Sufi referred to the sincerity found in love of Rabi 'ah. Rabi'ah made easy the path of al-Bisthami, al-Hallaj, al-Ghazali, Ibnu Arabi. Even Jalal al-Din alRumi put his art works and Sufism experiences in mahabbah as for Rabi ah.

تناول الباحث موحوع اعبدة عند ربعة العادوية ـ ففي القون الأول من الفجوي ننـأت الحياة

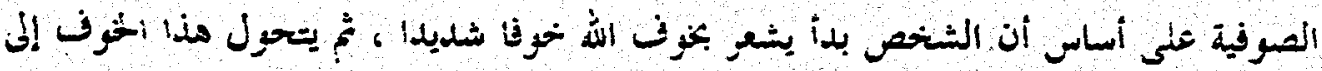

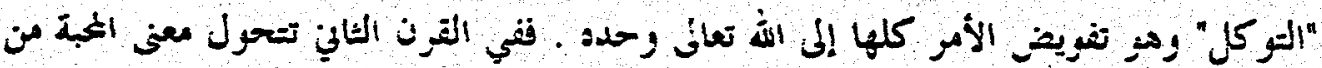

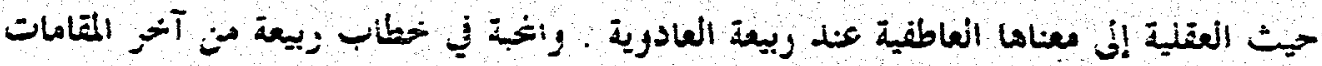

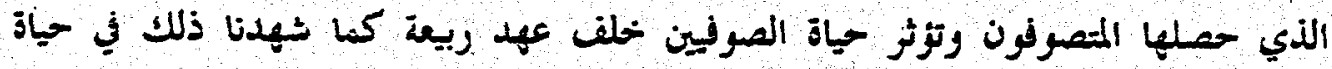
البسطامي والحلاجج والغزالي وابن العربي وشعر الحب الصصوفية لجلال الدين الرومي.

Kata Kunci: Mahabbah, Tasawuf, Maqam, Rintisan. Yogyakarta.

Mahasiswa Program Doktor Program Pascasarjana IAIN Sunan Kalijaga 


\section{A. Pendahuluan}

$T$ erdapat fenomena pergeseran pengamalan keagamaan yang cukup menarik dalam tasawuf yang sering diklaim sebagai pengamalan keagamaan paling luhur, bahkan penganutnya sering disebut "orang suci" (the saint). Ajaran tentang mahabbah adalah ajaran yang paling awal menampilkan pergeseran dalam dunia tasawuf.

Secara normatif, Islam memang mengajarkan mahabbah (cinta) kepada Allah swt. Misalnya dalam Q.S. Ali Imran: 31, 134 dan al-Ma'idah: 54. Nabi Muhammad saw juga mengajarkan agar seorang muslim mencintai Allah swt lebih dari yang selainn-Nya. Ajaran tersebut ditambah dengan janji imbalan yang begitu besar di dunia dan akhirat. ${ }^{2}$

Abd al-Hakim Hasan memberikan catatan bahwa mahabbah pada masa awal Islam diwujudkan dalam bentuk pelaksanaan segala ajaran dengan penuh ketulusan dan konsistensi, hanya mengharap balasan baik dan terhindar dari siksa Allah swt, atau bertujuan utama mendapat ridla-Nya. Sedang mahabbah kepada Allah swt. diyakini termanifestasi dalam bentuk anugerah rahmat, pahala, surga dan ridla-Nya, walaupun secara teologis tidak harus karena kewenangan mutlak-Nya. Mahabbah di abad pertama ini distilahkan dengan al-hubb al-'aqly (cinta rasional). ${ }^{3}$

Pada abad pertama, kehidupan sufistik atau juga dikenal dengan "kehidupan spiritual" (al-hayah al-rûhiyyah) didasarkan pada khauf (rasa takut) yang kemudian berkembang menjadi tawakkal (pasrah) kepada Allah swt. Karena itu mahabbah dinilai belum murni dan dewasa. Mahabbah masih bermakna kepatuhan karena rasa takut dan akhirnya pasrah. Pada abad II $\mathrm{H}$. mahabbah atau juga disebut al-h̆ubb al-ilâhi (cinta ilahi/divine love) berkembang dan mengalami pergeseran makna pada kutub yang lebih ekstrim. Mahabbah memiliki makna rasa cinta kepada Allah swt. karena Allah itu sendiri, tanpa ada pamrih. Hanya Allah swt. semata yang ada dalam? sanubarinya dan keinginannya adalah menyatu dengannya. Inilah yang disebut: al-hubb al-athify (cinta emosional). ${ }^{4}$

Tokoh yang dinilai merintis pergeseran makna mahabbah dari aqly (rasional) ke 'athify (emosional) adalah Rabi'ah al-'Adawiyah (95-185 H./713-

'Lihat Abu al-Wafa' al-Ghanimi al-Taftazani, 1976, Madkhal ila al-Tashowwuf alIslami, Kairo: Dar al-Tsaqafah.

2 Al-Qusyairi mengutip beberapa hadits, antara lain riwayat al-Bukhari, Muslim, alTurmudzi dan al-Hakim. Lihat Abd al-Karim al-Qusyairi, 1982, Al-Risalah al-Qusyairiyah, Kairo: Dar al-Khair, hal. 218.

3 'Abd al-Hakim Hasan, 1954, Al-Tashawwuf fi al-Syi'r al-'Arabi: Nasy'atuh wa Tathawwuruh hatta Akhir al-Qarn al-Tsâlits al-Hijry, Kairo: Maktabah Angelo al-Misriyah, hal. 290. hal. 219.

${ }^{4}$ Cinta jenis ini identik dengan taslim (pemasrahan diri) dan ridla (kerelaan). Ibid, 
801 M.). Ia adalah "satu-satunya" tokoh sufi perempuan dalam wacana tasawuf, walaupun sebenarnya banyak tokoh-tokoh sufi wanita lainnya yang sangat berpengaruh.

\section{B. Sejarah Hidup Rabî'ah.}

Rabî'ah dilahirkan sekitar 95-99 $\mathrm{H}^{6}$ di Bashrah, dari keluarga yang sangat asketik (zuhd). Ia lahir di sebuah rumah ekstra sederhana, tampak gulita, tanpa penerangan lampu sama sekali. Ternyata tak ada minyak untuk lampu. Sang ibu menyuruh ayahnya minta minyak kepada tetangga sebelah untuk malam itu saja. Tapi sang ayah yang telah berjanji tidak akan minta apapun kepada siapapaun -sesama manusia - hanya keluar, hanya berdiri di depan pintu tetangga dan kembali lagi sembari berkata: "mereka tidak mau membuka pintu." Dalam keadaan yang sangat prihatin itu, sang ibu menangis, sementara ia akan melahirkan. Sang ayah tertidur duduk, dan saat itulah ia bermimpi kedatangan Nabi Muhammad saw. dengan beberapa pesan. (1) agar tidak usah bersedih akan menjadi "ratu" kaum peremuan dan akan menjadi pimpinan dari tujuh puluh ribu umatnya, (2) agar menulis surat kepada 'Isa Zadzan (Gubernut Bashrah) untuk mengingatkan bahwa pada malam Jum'at tersebut ia lupa membaca shalawat seperti kebiasaannya. ${ }^{7}$ Karena itu, ia harus membayar denda kepadanya (ayah Rabi'ah) sebesar 400 dinar. Dia terbangun dan menangis kemudian menulis surat dan dikirimkan melalui punggawa istana. Selanjutnya anak yang baru lahir itu diberi nama Rabi'ah. Menurut Farid alDin Attar, itu dimungkinkan karena ia adalah anak keempat (al-bint alrabî'ah). ${ }^{8}$

Menerima surat tersebut, 'Isa langsung memerintahkan untuk memberikan 2000 dinar, sebagai tanda terima kasih atas peringatan terhadap kelalaiannya. 'Isa juga menyatakan ingin bertemu dan sangat simpati padanya dengan kesanggupan menyediakan segala keperluan keluarganya. Tapi

${ }^{5}$ Lihat Annemarie Schimmel, 2000, Dimensi Mistik dalam Islam, terj. Sapardi Djoko Damono dkk., Jakarta: Pustaka Firdaus, hal. 49. Margaret Smith menyebutkan begitu banyak tokoh sufi perempuan terkemuka sejak awal Islam. Antara lain Fathimah al-Zahra' al-Batoul (putri Nabi saw), Ummu Harram (istri 'Ubaidah bin Shamit), Rabi'ah al-Syami (sufi Syiria yang sering dikaburkan dengan Rabi'ah al-'Adawiyah), Sya'wanah (sufi Persia, sahabat Fudlail bin 'Iyadl), Nafisah (istri Ishaq bin Ja'far al-Shadiq). Selengkapnya lihat M. Smith, Rabi'ah, 1997, Pergulatan Spiritual Perempuan, terj. Jamilah Baraja, Surabaya: Risalah Gusti, hal. 157-184.

6 Menurut M. Smith, tahun kelahiran Rabi'ah tidak diketahui dengan pasti. Tapi dalam Ensiklopedi Islam, tegas dinyatakan tahun 99 H./713 M. Lihat Hafidh Dasuki dkk., 1997, Ensiklopedi Islam, Jakarta: Ichtiar Baru Van Hoeve, cet. ke-2, jld. IV, hal. 148.

${ }^{7}$ Biasanya dia membaca shalawat 100 kali tiap malam dan 400 kali khusus setiap malam Jum'at. Lihat A.J. Arberry, 1966, Muslim Saints and Mystic, London: Routledge \& Kegan Paul Ltd., hal. 41.

8 Ibid. Bandingkan dengan M. Smith, op. cit, hal. 7-8. 
peristiwa itu bukan merupakan awal kebahagiaan keluarga Rabi'ah. Karena saat menginjak besar, ayah dan ibunya meninggal dan kakak-kakaknya berpisah entah ke mana. ${ }^{9}$ Rabi'ah menjadi yatim piatu. Saat musim paceklik menimpa Bashrah, ia ditangkap oleh seseorang dan menjualnya sebagai budak dengan harga 6 dirham.

Sebagai budak, Rabi'ah menjalani hidupnya dengan bekerja berat di siang hari sambil berpuasa dan beribadah di malam hari. Sampai akhimya ia dibebaskan tanpa syarat oleh majikannya, karena pada suatu malam sang majikan melihat cahaya terang benderang di atas kepala Rabi'ah saat ia berdo'a. Do'a yang dipanjatkan Rabi'ah adalah:

Ya Allah. Tuhanku, Engkaulah Yang Maha Mengetahui keinginan dalam hatiku untuk selalu menuruti perintah-perintah-Mu. Jika persoalannya hanya terletak padaku, maka aku tidak akan henti-hentimya sesaat pun untuk beribadah kepada-Mu. Karena Engkaulah yang telah menciptakanku. ${ }^{10}$

Setelah melihat peristiwa itu, sang majikan tidak bisa tidur sampai pagi. Di pagi harinya, ia memanggil Rabi'ah dan membebaskannya. ${ }^{11}$ Setelah menikmati kebebasan, Rabi'ah memilih untuk konsentrasi pada kehidupan sufistik, menyepi, menjalani kehidupan asketik, tidak menikah sekalipun banyak yang melamarnya. Ia dikenal tidak suka menerima bantuan materi dari orang lain. Rabi'ah akhirnya menjadi tokoh sufi yang menjadi rujukan konsultasi ajaran dan pengalaman sufistik serta dikunjungi banyak orang. Bahkan para sufi terkemuka pada saat itu selalu datang untuk berdialog dengannya, seperti Sufyan al-Tsauri, Syaqiq al-Balkhi, Malik bin Dinar dan Hasan al-Bashri. ${ }^{12}$ Walaupun demikian, Rabi'ah bukan sama sekali meninggalkan aktivitas sosial. Karena terbukti ia masih melayani para tamu yang hendak berkonsultasi dan minta nasehat, ia juga sering memberikan ceramah-ceramah. Semuanya dilakukan jika sekiranya tidak memalingkannya atau menyibukkannya dari ibadah kepada Allah swt. serta mengikis rasa cintanya yang tak tertandingi kepada-Nya. Selain itu, ia dikenal sangat

9 Dalam riwayat lain, kakak-kakaknya juga meninggal karena kelaparan yang menimpa Bashrah waktu itu. Jamil Ahmad, 1994, Seratus Muslim Terkemuka, terj. Tim Pustaka Firdaus, Jakarta: Pustaka Firdaus, hal. 72.

${ }^{10}$ A.J. Arberry, op cit., hal. 48.

11 Ibid.

12 Menurut al-Huraifisy nama tokoh terakhir ini yang diragukan semasa dengan Rabi'ah. Karena menurut catatan para sejahrahwan, Hasan al-Bashri wafat pada $110 \mathrm{H}$ : Sedang Rabi'ah wafat $185 \mathrm{H}$. Umur Rabî'ah sekitar 90 tahun. Artinya kemungkinan mengenal Hasan al-Bashri hanya ketika berusia sekitar lima tahun. Lihat Syu'aib bin 'Abd al-'Aziz alHuraifisy, 104 H, Al-Raudl al-Fà'iq, Kairo: Dar al-Ma'rifah, hal. 117. 
dermawan, karena tidak mau terikat dengan segala yang bersifat material duniawi. Baginya segala kekayaan tidak berharga. ${ }^{13}$

Seperti kisah-kisah hidup seorang sufi yang identik dengan karamah (keistimewaan yang di luar kebiasaan), Rabî'ah juga dikenal banyak memiliki karâmah. Misalnya, untanya yang mati di tengah perjalanan menuju Mekkah untuk menunaikan ibadah haji, hidup kembali dengan do'anya, dua potong roti yang disajikan pada tamunya menjadi banyak dan mencukupi, jemarinya bisa memacarkan cahaya sehingga rumahnya yang tak berlampu bisa terang, bisa terbang dengan manaiki tikar, akrab dengan seluruh bintang buas. Kisah-kisah itu diceritakan oleh para sahabatnya yang juga kaum sufi dan orang-orang terdekatnya, walaupun Rabi'ah selalu berusaha menyembunyikannya. Karena ia sangat tidak menyukai popularitas. Baginya popularitas mencerminkan kesombongan dan cenderung menjadikan dunia sebagai tujuan. ${ }^{14}$

Pada masa tuanya, Rabi'ah tampak semakin mengundurkan diri dari segala aktivitas selain ibadah. Bahkan tubuhnya menjadi sangat lemah. Kemungkinan besar karena sikap asketiknya. Pada saat sakit menjelang wafatnya, ia menyuruh pembantunya, 'Abdah binti Abi Syumail, untuk tidak memberitahukan kepada siapapun bahwa ajalnya sudah dekat. Kepada orang yang menjenguknya, ia menceritakan bahwa sakit baginya adalah kenikmatan. Karena itulah yang dikehendaki oleh Yang Dicintainya (Allah swt.). Karena sakitnya bersumber dari rasa cinta yang amat dalam, maka tak ada yang bisa menyembuhkannya di dunia ini. Saat ajal menjelang tiba, ia meminta seluruh yang menjenguk untuk keluar dan mereka menutup pintu. Saat itulah mereka mendengarnya membaca dua kalimat syahadat. Setelah itu, mereka mendengar suara aneh, membaca ayat:

Wahai jiwa yang tenang, kembalilah kepada Tuhanmu dan berpuas-puaslah denganNya, masuklah bersama golongan hamba-hamba-Ku dan masuklah ke dalam surgaKu. (Q.S. $89: 17-30)^{15}$

Rabi'ah meninggal pada tahun $185 \mathrm{H} . / 801 \mathrm{M}$. dalam usia mendekati 90 $\therefore=$ tahun, dan dimakamkan di Bagdad. ${ }^{16}$ Tapi tentang tahun wafatnya, masih terdapat silang pendapat. Menurut al-'Aththar, ada yang berpendapat tahun 135

\footnotetext{
${ }^{13}$ Lihat M. Smith, op.cit., terutama Bab II dan III.

${ }^{14}$ lbid., Bab IV.

15 Ibid.
}

${ }^{16}$ Ada perselisihan pendapat tentang makam Rabi'ah. Ada yang mengatakan tidak diketahui, ada yang mengatakan di Syam, dan ada pula yang di Baghdad. Sangat mungkin kerancuan itu akibat kerancuan nama Rabi'ah dengan Rabi'ah al-Syami Lihat Mohamad Atiyah Khamis, 1993, Penyair Wanita Sufi, Rabi'ah al-'Adowiyah, terj. Anas Mahyuddin, Jakarta: Pustaka Firdaus, hal 81. 
H./752 M. dengan selisih mencolok (30 tahun). ${ }^{17}$ Ini merupakan salah satu dampak kerancuan nama antara Rabi'ah al-'Adawiyah (Bashrah) dengan Rabi'ah (sering dibaca Ray'ah, dengan titik dua[ya']) binti Isma'iel al-Syami (Syam). Karena itu, dari kajian M. Smith dapat dicatat beberapa hal penting. (1) Nama Rabi'ah al-'Adawiyah tidak dikaitkan dengan nama ayahnya. sebagaimana lazimnya orang yang pernah menjadi budak. Sedang Rabi'ah yang satunya dikaitkan kepada ayahnya, Isma'iel, sehingga menjadi Rabi'ah binti Isma'iel. (2) Rabi'ah al-'Adawiyah tinggal di Bashrah dengan nisbat suku 'Adiy, sedang Rabi'ah binti Isma'iel tinggal di Syiria sehingga sering disebut Rabi'ah al-Syami. (3) Rabi'ah al-'Adawiyah tidak memiliki suami, sedang Rabi ah binti Isma'iel adalah istri Ahmad bin Abi al-Hawwari. yang menurut banyak ahii wafar 30 tahun lebih awal. (4) Rabi'ah al-'Adawiyah dikebumikan di Baghdad dan Rabi'ah binti Isma'iel dikebumikan di Bukit Thur Yerussalem (salah satu obyek ziarah terkenal). ${ }^{18}$

\section{Jalan Menuju Puncak}

Walaupun mahabbah menjadi tema sentral dalam tasawuf Rabi'ah. bukan berarti ia telah mencapai kesempurnaan sejak awal karir sufistiknya. Mahabbah dalam wacana tasawuf adalah maqam (tingkat) tertinggi dalam ajaran Rabi'ah. Untuk mencapainya harus melalui maqam-maqam yang lebih rendah. Secara umum, mahabbah terbagi menjadi tiga tingkat:.(1) mahabbah orang biasa, yitu selalu mengingat Tuhan; (2) mahabbah orang shiddiq, yaitu mahabbah yang mampu membuka tabir antara manusia dan Tuhan, menghilangkan sifat-sifat diri dan hati penuh dengan rasa rindu kepada-Nya: (3) mahabbah orang urif yaitu mahabbah yang mengetahui betui terhadap Tuhan, yang dirasa bukan lagi cinta, tapi Diri yang dicinta. 19

Kata mahabbah dan derivasinya telah diucapkan Rabi'ah sejak awal. Tapi hal itu tidak lepas dari jalan (tharigat) dan tahapan-tahapan (magamat) yang dilaluinya. $\mathrm{Di}$ situlah terlihat pandangan-pandangan Rabi'ah tentang ajaran lain selain mahabbah. Tahapan-tahapan itu menurut rumusan Berdasar pandangan al-Sarraj al-Thusi, tahapan-tahapan tersebut adalah: taubah, wara? zuhd, faqr, shabr, tawakkal dan ridla. ${ }^{20}$

Arberry, op.cir., hal. 39.

${ }^{18}$ Lihat selengkapnya, M. Smith, op. cit., hal. 160-163. Walaupun demikian, tahun wafat Rabi'ah binti Isma'iel masih diragukan jika dihubungkan dengan tahun masa hidup suaminya dari $164 \mathrm{H}$ sampai $264 \mathrm{H}$.

19 Dikutip Harun Nasution dari al-Sarraj al-Thusi. Lihat Harun Nasution, 1989. Filsafat dan Misticisme dalam Islam. Jakarta: Bulan Bintang, hal. 76.

$2^{20}$ Lihat Abu Nast al-Sarraj al-Thusi, 1960, Al-Luma', Kairo: Dar al-Kutib. alHaditsah, hal. 12. Para ulama memang tidak memberikan urutan dan jumlah yang sama di antra maqamat tersebut. Misalnya rumusan al-Ghazali, Al-Kalabadzi dan al-Qusyairi. 


\section{Taubah}

Taubah adalah tahap pertama yang harus dilalui oleh orang yang hendak memasuki dunia sufi. Ia adalah pembersihan dosa. Karena dosa adalah kegelapan, yang tidak bisa menyatu dengan "cahaya": ${ }^{21}$ Menurut Rabi'ah, dosa adalah penghalang dari Tuhan. Karena itu, seharusnya orang tidak sempat lagi menikmati kehidupan. Orang harus sedih, jika ia tidak bisa sedih. Orang yang hanya mengeluh tentang dosa, tapi masih bisa hidup senang, maka ia dusta. ${ }^{22}$ Kesedihan ketika mengingat dosa membuat Rabi'ah terus menangis, bukan karena takut pada siksa neraka. Tapi karena takut berpisah dengan Kekasihnya. Keterpisahan dengan Tuhan adalah siksaan terberat bagi Rabi'ah. ${ }^{23}$ Maka orang yang tidak ingin berpisab dengan Tuhan harus bertaubat dengan penuh ketulusan. Walaupun demikian taubah sepenuhnya merupakan anugerah Tuhan sebagai al-taqdir al-khair (ketetapan baik). ${ }^{24}$

\section{Wara'}

Wara' adalah sikap hati-hati dari segala yang syubhat (tidak jelas status halal-haramnya). Bahkan bagi seorang sufi, sesuatu yang tidak jelas-jelas halal akan ditinggalkan. Lebih dari itu, segala yang halal tapi dapat mengganggu hubungannya dengan Tuhan akan ditinggalkan. ${ }^{25}$ Sikap seperti inilah yang ditunjukkan Rabi'ah ketika menolak bingkisan emas dari Hasan al-Bashri, karena takut memalingkan perasaannya dari Tuhan ke harta. ${ }^{26}$ Ketika akan memasak sop, dan tidak punya bawang, tiba-tiba seekor burung mengantar bawang kepadanya. Tapi Rabi'ah tidak mau makan sop yang disajikan pelayannya, karena khawatir bawang itu hanya tipu muslihat. ${ }^{27}$ Rabi'ah juga merasa gelisah karena telah menjahit pakaiannya yang sobek dengan menumpang cahaya lampu rumah penguasa. Akhimya ia menyobek pakaiannya lagi. ${ }^{28}$

${ }^{21}$ Al-Ghazali, 1986, Ihya' Ulum al-Din, Surabaya: Hidayah, juz IV, hal. 12.

22 Seperti dikatakan Rabi'ah saat mendengar keluhan Sufyan al-Tsauri: "Alangkah sedihnya hatiku." Bagi Rabi'ah, kata-kata itu gombal, karena Sufyan masih bisa terlihat bahagia. Lihat al-Taftazani, op.cit., hal. 100.

${ }_{23}$ Lihat Farid al-Din al-'Aththar, 1905, Tadzkirat al-Auliya', London: Luzac, Vol. I, hal. 73. Rabi'ah terkenal sangat sering menangis karena susah. Api adalah lambang penderitaan baginya. Ketika ia mendengar kata api disebut-sebut, ia pingsan. Di tempat sujudnya selalu basah kuyup karena banjir air mata. Al-Yafi'ie, $1324 \mathrm{H}$, Raudl al-Riyahin, Kairo: Dar al-Ma'rifah, hal. 101.

${ }_{24}^{4}$ Al-Taftazani, op. cit., hal. 101.

${ }^{25}$ Al-Qusyairi mengutip pemyataan al-Syibli. Lihat al-Qusyairi, op. cit., hal. 110.

${ }^{26}$ Abd al-Mu'in Qandil, 1993, Figur Wanita Sufi, terj. M. Sofyan Amrullah, Pustaka Progressif, hal. 111 .

${ }^{27}$ A.J. Arberry, op cit., hal. 54. 


\section{Zuhd}

Dari wara' akan meningkat lagi ke zuhd, yaitu meninggalkan segala keduniawian untuk terus mendekatkan diri kepada Allah swt. ${ }^{29}$ Bagi seorang yang hendak memasuki dunia sufi, keduniawian harus ditinggalkan, setidaknya karena dua alasan pokok: (1) karena dapat mengalihkan perhatian dari Allah 30 mengganggu ibadah, ${ }^{31}$ beban dan jerat pengembaraan spiritual; ${ }^{32}$ (2) karena tidak membuat kaya hakiki, sekalipun memiliki seluruh dunia, sebab karena ia fana ${ }^{33}$ Bagi Rabi'ah, zuhd dijalani bukan semata untuk membersihkan hati dari keduniawian, tapi lebih karena ketakutan berpisah dengan Allah swi. karena sibuk dengan dunia. Karena itu, ia tidak pernah memperbincangkan urusan dunia dari sisi baik dan buruknya. ${ }^{34}$ Bahkan ia sampai tidak peduli dengan perlengkapan rumah tangganya. ${ }^{35}$

\section{Faqr}

Al-Syibli memberikan pengertian faqr dengan "tidak adanya rasa butuh kecuali kepada Allah. ${ }^{36}$ Bagi Rabi'ah, meminta sesuatu kepada orang lain adalah pantangan. ${ }^{37}$ Bahkan Rabi'ah merasa malu untuk meminta sesuatu yang

${ }^{29}$ Hal itu tampak ketika Rabi'ah menolak tinggal di rumah mewah hasil renovasi seorang saudagar kaya. "Aku takut hatiku tertambat padanya, sehingga aku disibukkan oleh dunia," jawaban tegas Rabi'ah. Farid al-Din Aththar, op. cit., hal. 66. Karena tujuan hidupnya hanya Allah semata, sehingga segala hal yang mungkin mengganggu harus ditinggalkan. AiGhazali, op. cit., hal. 291.

${ }^{30}$ Karena itu, ia juga menolak lamaran gubernur Bashrah dan menjanjikan mas kawin 100.000 dinar plus gaji 10.000 dinar perbulan. Tapi Rabi'ah menolaknya, bahkan sekalipun sang gubernur akan menjadi budaknya. Lihat M. Smith, op. cit. Hal. 14.

${ }^{31}$ Sebagaimana diceritakan dalam mimpinya tentang sebuah pohon yang sangat indah dengan tiga buahnya yang memancarkan cahaya putih, kuning dan merah serta 18 buah yang jatuh. Seandainya pada bagian dari shalatnya (sepanjang malam sampai shubuh kemudian tertidur) ia tidak memikirkan adonan yang dibuatnya, buah-buahan itu tidak akan jatuh dan akan tampak lebih menakjubkan. Lihat selengkapnya dalam Abu Thalib al-Makki, 1978, Qut al-Qulub fi Mu'amalat al-Mahbub, Beirut: Dar al-Fikr, juz II, hal. 103.

32. Suatu hari Rabi'ah membuang uangnya ke Sungai Tigris setelah orang yang disuruhnya membeli baju, kembali lagi dan menanyakan warnanya. Dia tidak mau lagi terikat dengan keduniawian sekecil apapun. Persoalan warna saja dapat membuat manusia tidak merdeka. Al-'Aththar, op.cit., hal. 68.

${ }^{33}$ Pandangan itu tercermin dari jawaban Rabi'ah ketika ditanya Sufyan al-Tsauri tentang apa yang harus dilakukan seorang hamba jika ingin dekat dengan Allah. Rabi'ah menjawab: "seorang hamba tidak boleh memiliki apa-apa dan sekalilpun memiliki seluruh dunia ia tidak akan kaya dibuatnya." Lihat M. Smith, op. cit., hal. 96.

${ }^{34}$ Rabi'ah menyatakan rasa tidak suka memperbincangkan baik buruk dunia kepada para penjenguknya saat dia sakit. Ketika itu para penjenguk berbicara tentang keburukan dunia untuk menghibur Rabi'ah. Al-'Aththar, op. cit., hal. 72.

${ }^{33}$ Pembantunya mengeluh karena tidak mendapatkan pisau di dapur dan Rabi'ah tidak peduli lagi dengan hal itu. Ibid., hal. 68.

${ }^{36}$ Al-Qusyairi, op. cit., hal. 276.

${ }^{3 ?}$ Lihat M. Smith, op. cit., hal. 26. 
bersifat duniawi kepada Allah, apalagi kepada makhluk-Nya. ${ }^{38}$ Bahkan Rabi'ah pernah menyatakan bahwa ia telah empat puluh tahun berjanji kepada Allah untuk tidak meminta apapun kecuali kepada-Nya. ${ }^{39}$ Untuk sekedar hidup, tidak perlu meminta-minta bantuan orang lain. Allah swt. telah menjaminnya.

\section{Shabr}

Sikap fagr yang sempurna akan mengantar pada sikap shabr. Shabrmenurut al-Qusyairi-- terbagi dua: (1) dalam menjalankan perintah dan larangan Allah, (2) dalam menghadapi segala ketentuan Allah. ${ }^{40} \mathrm{Hal}$ ini telah ditunjukkan oleh Rabi'ah dalam ibadah-ibadahnya, shalat dan dzikir sepanjang malam dan bepuasa di siang hari. Lebih dari itu, bagi Rabi'ah, segala kehidupannya adalah kehendak Allah. Karena itu harus diterima, tanpa ada usaha menentangnya. ${ }^{41}$

\section{Tawakkal}

Shabr yang sungguh-sungguh akan melahirkan tawakkal (pasrah kepada Allah). Rabi'ah telah menunjukkan betapa ia hanya menjalani segala ketentuan yang diterimanya, sekalipun berupa musibah. ${ }^{42}$ Segala yang terjadi adalah kehendak Allah, dan tugas seorang hamba adalah menerimanya dengan penuh ketulusan. ${ }^{43}$

\section{Ridla}

Puncak táwakkal adalah ridla (rela) atas segala yang dikehendaki Allah swt. Bagi Rabi'ah, kesulitan hidup memang telah digariskan oleh Allah, dan Dia sepenuhnya mengetahui. Karena itu segala bentuk cobaan tidak boleh

${ }^{38}$ Jawaban Rabi'ah ketika ada seseorang yang menawarkan bantuan apa saja yang dibutuhkan olehnya. Lihat al-Taftazani, op. cit., hal. 99.

39 Jawaban Rabi'ah ketika pembantunya minta idzin untuk minta bawang kepada tetangga ketika akan membuat sop. A.J. Arberry, op. cit., hal. 54.

${ }^{40}$ Al-Qusyairi, op. cit., hal. 145.

41 Jawaban terhadap anjuran Malik bin Dinar agar mohon diringankan penderitaannya kepada Allah swt. Al-'Aththar, op. cit., hal. 71.

${ }_{42}$ Rabi'ah pernah menegur seorang pemuda yang mengikat kepalanya dan mengeluh. Lihat al:-Aththar, op cit, hal. 68.

43 Hal itu tampak dari penolakannya terhadap tawaran. Malik bin Dinar yang menawarkan bantuan untuk meringankan penderitaannya. "Karena Dia mengetahui keadaanku, mengapa aku harus mengingatkan-Nya? Apa yang diinginkan-Nya, kita harus menerimanya." Kata Rabi'ah. Ibid., hal. 71. Dalam kisah lain, “Abd al-Wahid bin Amir bersama Sufyan alTsauri datang ke Rabi'ah menjenguk Rabi'ah dan menganjükannya agar memohon kepada Allah untuk meringankan penderitaannya. Tapi Rabi'ah menolak karena Allah tahu betul kondisinya dan Dia:memang menghendaki itu. Lihat Michael A. Sells, 1996, Early Islamic Mysticism, New York: Paulist Press, hal. 167. 
memadamkan rasa cinta kepada-Nya ${ }^{44}$ Bagi orang yang telah mencapai maqam ridla, musibah atau penderitaan dan kenikmatan atau anugerah adalah sama. Semuanya sama-sama diterima dengan senang hati sebagai kehendak Allah. ${ }^{45}$ Dengan ridla dalam hatinya, Rabi'ah mengharap Allah swt. ridla kepadanya. ${ }^{46}$

\section{Mahabbah sebagai Ajaran Inti.}

Dalam wacana sufi, Rabi'ah disebut sebagai peletak ajaran mahabbah, karena menjadikannya sebagai tema sentral ajarannya dengan nuansa makna yang baru lebih dalam dan sejati. Walaupun demikian pengertian mahabbah tidak pernah didefinisikan secara lengkap dalam berbagai ungkapannya. Ia pernah menyatakan bahwa cinta berasal dari keazalian menuju kebadian. ${ }^{47}$ Dalam kesempatan lain, Rabi'ah membagi cinta menjadi dua: (1) hubb alhawa, cinta yang disebabkan oleh rasa rindu hati, (2) hubb al-ahl, cinta karena Allah memang layak dicinta. ${ }^{48}$ Mahabbah yang pertama adalah rasa cinta yang disebabkan oleh kebaikan dan karunia yang diberikan oleh Allah swt. Mahabbah jenis ini bersifat sementara. Sedang mahabbah yang kedua adalah cinta karena tersingkapnya tabir sehingga keindahan Allah terlihat dan terasa. Inilah cinta sejati yang menjadi tujuan Rabi'ah dan para sufi. Mahabbah jenis ini bersifat abadi dan sejati. ${ }^{49}$

Di samping dalam sya'ir-sya'ir dan pernyataannya, ajaran mahabbah Rabi'ah juga dapat terlihat dari sikap, pola hidup dan do'a-do'anya. Dalam kehidupannya, Rabi'ah telah menunjukkan pola hidup yang sangat sufistik, karena kekahawatiran pada pembelokan kecenderungan hati. Sementara dalam berbagai sya'ir dan ungkapannya, kata mahabbah berikut derivasinya menjadi suku kata yang dominan. Dari semua sumber tersebut, dapat ajaran mahabbah

44 Suatu ketika Rabi'ah berkata: "Seandainya Engkau akan memisahkanku dengan-Mu melalui penderitaan, aku tidak akan berhenti sebagai kekasih-Mu." Lihat M. Smith, op. cit; hal. 72 .

45 Ketika musibah sama dengan nikmat, maka orang itu telah mencapai ridla Demikian jawaban Rabi'ah ketika ditanya Sufyan al-Tsauri. Lihat al-Qusyairi, op. cit, hal 163.

${ }^{46}$ Rabi'ah menegur Sufyan al-Tsauri yang berdo'a: "Ya Allah ridlailah hamba:" Rabi'ah berkata: "Apakah engkau tidak malu minta ridla kepada Dzat yang engkau tidak ridla kepada-Nya." Lihat Al-Kalabadzi, 1960, Al-Ta'arruf li Madzhab Ahl al-Tashawwuf, Kairo: Dar al-Ma'rifah, hal. 107. Artinya, ridla harus timbal balik antara Allah dan hamba, AlTaftazani, op. cit., hal. 101.

47 Dalam pengertian ini, Rabi'ah menghubungkan ajaran mahabbah dengan Q.S 5:54). Lihat al-'Aththar, op. cit, hal. 67 .

${ }^{48}$ Syair ini sangat terkenal dan banyak dikutip dalam buku tasawuf. Lihat misalnya alMakki, op. cit., juz II, hal: 57. IV, hal. 267

${ }^{49}$ Al-Ghazali mengulas cukup panjang sya'ir tersebut. Lihat al-Ghazali, op. cit., juz 
dapat dirumuskan dalam tiga hal. Pertama, Allah swt. adalah Dzat yang semestinya dicintai, karena Dia yang menciptakan, 50 dan karena ketakterhinggaan rahmat yang dianugerahkan. ${ }^{51}$ Tujuan utama seorang sufi bukanlah anugerah itu sendiri, melainkan terbukannya "tabir" (hijab) dan "kebersamaan" dengan-Nya. ${ }^{52}$ Karena hal itu merupakan kebahagiaan hakiki yang sangat didambakan. Hal itu terkait dengan doktrin khauf (takut) dan raja' (harapan), yang berarti ketakutan berpisah.

Kedua, mahabbah sejati terwujud dalam pengabdian tulus, tidak berharap apa-apa, kecuali untuk bersatu dengan Yang Dicintai. Motivasi pengabdian bukan pahala atau surga dan takut siksa atau neraka. ${ }^{53}$ Bahkan terdapat kisah populer bahwa Rabi'ah membawa obor dan setimba air. Ketika ditanya, Rabi'ah menjawab bahwa ia hendak membakar surga dan menyiram neraka sehingga tak ada lagi ketakutan pada ancaman siksa dan harapan balasan kenikmatan. Dengan demikian umat manusia bisa mengabdi dengan tulus pada Allah swt. ${ }^{54}$ Di samping ketulusan mengabdi, mahabbah sejati juga tampak dalam sikap ridla terhadap segala yang menimpa dan dianggap sebagai hal yang memang dikehendaki oleh Allah swt. Karena dengan ridla, seorang hamba akan merasa bahagia saat mendapat musibah seperti kebahagiaan saat mendapat kenikmatan. ${ }^{55}$ Musibah dan nikmat sama saja dan tidak akan memberikan dampak yang berbeda. Dalam kondisi menderita sekalipun, tidak akan terbersit keinginan untuk mohon agar penderitaan yang menimpanya dihilangkan dan tidak akan berprasangka buruk kepada Allah swt. saat

${ }^{50} \mathrm{Hal}$ itu tercermin dalam kata-kata do'anya ketika ia masih menjadi budak, sehingga turun cahaya ke kamarnya dan keesokan harinya dimerdekakan oleh majikannya karena melihat peistiwa itu. Lihat Aththar, op. cit, hal. 61 .

${ }^{51}$ Salah satu sya'ir yang mengungkapkan hal ini dikutip oleh al-Huraifisy, op. cit., hal. 213

52 Tentang "kebersamaan" sebagai dambaan seorang sufi, al-Huraifisy mengutip pernyataan Rabi'ah. Lihat al-Huraifisy, Ibid, hal. 214. Tentang terbukanya "tabir" sebagai tujuan, lihat al-Taftazani, op. cit., hal. 104 dan 102.

${ }^{53}$ Rabi'ah berkata: "Seorang hamba yang mengabdi kepada Allah swt karena surga adalah hamba yang bodoh." Al-'Aththar, op. cit., 67. Dalam kesempatan lain, ketika ditanya Sufyan al-Tsauri tentang iman, Rabi'ah menjawab: "Takut pada neraka berarti pekerjaan siasia dan ingin surga berarti tidak tulus." Lihat al-Makki, op. cit., hal. 57. Bahkan dalam sebuah do'anya, Rabi'ah menyatakan: "Tuhanku, jika aku menyembah-Mu karena takut pada neraka, bakarlah aku di dalam Jahanam. Jika aku menyembah-Mu karena ingin surga, jangan berikan surga itu kepadaku. Tapi jika aku menyembahmu karena cintaku pada-Mu, jangan halangi aku dari keindahan abadi-Mu, Tuhanku." Lihat Mohammad Mushthafa, 1945, Al-Hayah alRuhiyah fi al-Islam, Kairo: Dar al-Fikr al-'Arabi, hal. 18

${ }_{54}$ Lihat M. Smith, op. cit., hal. 47. hal. 195.

${ }^{55}$ Demikian jawaban Rabi'ah ketika ditanya tentang ridla. Lihat al-Qusyairi, op.cit., 
menerima musibah. ${ }^{36}$ Segalanya akan terasa nikmat, karena datang dari Yang Dicintai dengan cinta sejati.

Ketiga, mahabbah sejati akan menyingkirkan segala yang selain Dzat yang dicintai sampai tak ada sama sekali ruang untuk yang lain dalam sanubari. Hal itulah yang terlihat dalam pola hidup sufistik Rabi'ah dengan tidak adanya perhatian sama sekali kepada yang lain selain Sang Kekasih. Tak ada sedikit ruang pun, sekalipun untuk mencintai Nabi Muhammad saw. ${ }^{57}$ Lebih dari itu, dari begitu penuhnya hati dengan rasa cinta, sampai tidak ada ruang untuk untuk membenci syetan sekalipun. ${ }^{58}$ Segalä ruang hati hanya untuk Allah swt, sehingga segala yang diperbuat adalah pengabdian untuk terus mendekat dan menuju penyatuan dengan Allah swt., Dzat yang sangat dicintai dengan tulus.

\section{E. Mahabbah sebagai Rintisan Tasawuf Sejati.}

Kenyataannya, mahabbah telah menjadi warna kehidupan sufistik Rabi'ah sejak awal. Ketika menjadi budak, ia telah banyak mengekspresikan rasa cintanya kepada Allah swt. dalam lantuman do'a. Tapi rasa cinta masa awal itu masih sangat kental dengan warna syari'ah (hubb al-syari'ah) dan berharap ridla-Nya. Baru dalam perkembangannya, harapan itu semakin tinggi menjadi "terbukanya tabir" (kasyf al-hijâb) dan berujung pada pelenyapan diri dalam "api cinta".

Di sinilah letak arti penting Rabi'ah. Pada zamannya ia adalah tokoh yang mampu mencapai tingkat paling tinggi dalam kehidupan sufistik di antara tokoh-tokoh sufi lain seperti Hasan al-Bashri, Sufyan al-Tsauri, Syaqiq alBalkhi dan Dzun Nun al-Mishri, Ibrahim bin Adham; Malik bin Dinar, Malik bin 'Iyadl. Itu bisa dilihat dari kenyataan bahwa mereka sering berkonsultasi dan banyak menanyakan hal-hal yang terkait dengan pengalaman dan pengetahuan sufistik. Bahkan Rabi'ah sering mengoreksi, menegur dan meluruskan hal-hal menyimpang menurut standar kaum sufi yang mereka lakukan.

Dengan mahabbah dalam makna khasnya, tidak berlebihan jika ia sering dinilai sebagai orang pertama yang merubah asketisme suram (somber

${ }^{56}$ Keyakinan seperti itu semakin tegus dalam hati Rabi'ah, terutama ketika ia berdo?a: "Ya Allah, apakah Engkau akan membakar hati yang mencintai-Mu?". Setelah itu ia mendengar suara yang menganjurkannya agar tidak buruk sangka (su' al-dzan) kepada Allah swt.. Ibid,, hal. 328. Dikutip juga oleh al-Taftazani, op. cit.; hal. 102.

57 Rabi'ah pernah menyatakan tak bersisa ruang dalam hatinya untuk Nabi Muhammad saw, ketika ia bermimpi bertemu didatangi Nabi saw dan menanyakan, apakah Rabi'ah mencintainya. Al-'Aththar, op. cit.; hal. 67.

58 "Rasa cintaku kepada Allah swt. tidak menyisakan ruang untuk membenci syetan sekalipun." Begitu penegasan Rabi'ah. Ibid. Lihat juga Michael A. Sells, op.cit., hal. 163. 
ascetism) menuju cinta mistisisme kasih sejati (genuine love misticism)..$^{59} \mathrm{Jenis}$ cinta semacam ini belum pernah dirumuskan dan dialalmi oleh kaum sufi sebelumnya, apalagi kaum formalis ortodok yang paling jauh hanya berharap ridla-Nya sehingga mendapat balasan kebahagiaan di akhirat. Rabi'ah mampu menenggelamkan diri dalam cinta agung (consumed in sublim love) untuk menampilkan kehidupan yang lebih mulia. ${ }^{60} \mathrm{Rabi}$ 'ah mencapai taraf cinta sejati itu dengan shalat, dzikir, do'a-do'a dan pola hidup sufistik. Ia tidak pernah berguru kepada tokoh sufi lain pada masanya. Karena kondisi mudanya (sebagai budak) tidak memungkinkan dan setelah bebas ia menjalani pengasingan diri. Bahkan yang mengundang decak kagum, bagaimana orang yang tidak pernah berguru kepada siapapun bisa melahirkan ajaran-ajaran begitu tinggi. $^{61}$

Inilah pergeseran paradigma (paradigm shift) pertama dalam dunia tasawuf, yang diwarnai oleh makna baru mahabbah dari "rasional" ( $a q l i)$ dan berpamrih ke "emosional" ( $a t h i f i)$ yang benar-benar tulus. Dengan itu Rabi'ah adalah pembuka jalan bagi mistik dalam Islam dalam arti sebenarnya, yaitu mencapai tujuan penyatuan dengan al-Haqq. Menurut K. Armstrong mahabbah Rabi'ah merupakan rumusan baru mendekati Tuhan yang sebenarnya akrab dengan tradisi Kristen. ${ }^{62}$ Dengan rintisan ini pula lahir tokoh-tokoh besar yang menyempurnakan perwujudan tasawuf (penyatuan dengan Allah swt:) seperti Abu Yazid al-Basthami dengan ajaran ittihad-nya atau al-Hallaj dengan hululnya. Walaupun akar ajaran ini sudah terdapat dalam ajaran "cinta suci" (alhubb al-khalish) dari Ja'far al-Shadiq dan Rabi'ah dinilah sebagai orang yang berjasa mengembangkannya menjadi lebih jelas dan populer. ${ }^{63}$

Capaian Rabi'ah dengan mahabbah -nya memang belum mencapai penyatuan diri (ittihad) atau rasa lenyap diri (fana) dalam. Allah swt. seperti yang dicapai Abu Yazid al-Basthami dan Abu Mansur al-Hallaj. Karena kondisi itu umumnya ditandai dengan lahimya "ungkapan-ungkapan ganjil yang keluar di luar kesadaran pengucapnya" (syathahat). Segala bentuk pernyataan Rabi'ah masih dalam kerangka "aku" dan "engkau" atau simbolsimbol lawan bicara yang lain. Sedang ciri khas ungkapan-ungkapan orang yang telah sampai ke puncak karier sufi adalah tidak adanya lagi dikotomi "aku", "Engkau" dan "Dia". Yang ada hanya "Aku", sebagai representasi Allah

34.

${ }^{59}$ Annimarie Schimmel, My Soul is a Woman, New York: H. Ray Continuum, hal.

${ }^{60}$ Widah el-Sakkakini, 1982, First among Sufis, the Life and Thought of Rabi'a alAdowiyya, terj. Nabil Safwat, London: Octagon Press, hal. 58.

61 Ibid., hal. 67.

${ }^{62}$ Karen Armstrong, 1993, A History of God, New York: Ballatine Books, hal. 225.

${ }^{63}$ Lihat 'Abd al-Qadir Mahmud, 1946, Al-Falsafah al-Shuffyah fi al-Islam, Kairo: Dar al-Fikr al-'Arabi, hal. 165 
swt. Dirinya tidak ada lagi. Ungkapan Rabi'ah masih lebih pada kerangka tauhid dan tajrid (pelenyapan selain Allah swt). Paling jauh ungkapan Rabi'ah hanya sampai ke tingkat tajdifat (pengingkaran karunia) yang oleh para penentang tasawuf dikategorikan al-makr al-khafi (dusta samar), belum sampai pada syathahat yang termasuk pada kategori kafir dan darahnya halal. ${ }^{64}$ Ada juga yang menggolongkan ungkapan-ungkapan Rabi'ah sebagai syathahat, tapi dalam pengertian syathahat maknawi, bukan syathahat lafdzi, walaupun Rabi'ah juga pernah mengatakan bahwa ia sudah menyatu dengan Allah swt. ${ }^{65}$

Nilai cinta yang tulus dalam kehidupan sufistik memberikan pengaruh besar pada perjalanan tasawuf sesudahnya. Seluruh sufi mengacu pada ketulusan tanpa pamrih yang terkandung dalam cinta Rabi'ah. Rabi'ah telah memuluskan jalan al-Basthami, al-Hallaj, al-Ghazali, Ibnu :Arabi. Bahkan Jalal al-Din al-Rumi mendasarkan karya seni dan pengalaman tasawufnya pada. mahabbah versi Rabi'ah. ${ }^{66}$

\section{F. Penutup}

Dari uraian di atas secara sederhana dapat ditarik garis besar bahasan: (a) Rabi'ah adalah tokoh besar, bahkan terbesar, dalam tasawuf abad II H, (b) Rabi'ah adalah perintis jalan baru sufi dengan ajaran mahabbah dalam pengertian baru sehingga tasawuf menjadi mistik Islam yang sebenarnya. (c) Mahabbah menurut Rabi' ah adalah cinta tanpa pamrih, mengabdi kepada Allah swt. tanpa berharap apapun, surga atau neraka sekalipun. Cinta sejati hanya berharap Allah sebagai "Yang Dicinta" (d) Puncak mahabbah adalah gerbang awal menuju ittihad dengan Allah swt. sebagai tujuan akhir dan puncak perjalan sufi. Dengan begitu Rabi'ah baru sampai pada gerbang ittihad, belum masuk ke dalamnya, sebagaimana terlihat pada tokoh sufi berikutnya. Tapi Rabi'ah-lah yang merintis jalan bagi para sufi berikutnya sehingga mencapai puncak perjalanan spiritualnya.

${ }^{64}$ Unsur-unusr syathahat secara umum adalah: (1) suka cita yang luar biasa, (2) lahir dari pengalaman menyatu, (3) dalam keadaan "mabuk" spiritual, (4) bersumber dari bisikan batin tentang "penyatuan" sehingga ia menggantikan peran dan berposisi di posisi Tuhan, (5) semuanya berlngsung di luar kesadaran. Ungkapan-ungkapannya -bisanya--: (1) memakan kata ganti orang pertama (dlamir mutakallim), (2) terdengar ganjil sebagai secara eksplisit. Lihat Abd al-Rahman al-Badawi, 1976, Syathahat al-Shufiyah, Kuwait: Wakalah al-Mathbu'ah, hal. 26 dan 10-11.

${ }^{66}$ Lihat 'Aththar, op.cit., hal. 66.

Mizan, hal. 148-152. 


\section{DAFTAR PUSTAKA}

Ahmad, Jamil, 1994, Seratus Muslim Terkemuka, terj. Tim Pustaka Firdaus, Jakarta: Pustaka Firdaus.

Arberry, A.J., 1966, Muslim Saints and Mystic, London: Toutledge \& Kegan Paul Ltd.

Armstrong. Karen. 1993, A History of God, New York: Ballatine Books.

'Aththar, Farid al-Din al-, 1905, Tadzkirat al-Auliya'. London: Luzac.

Badawi, Abd al-Rahman al-, 1976, Syathahat al-Shufiyah, Kuwait: Wakalah al-Mathbu'ah.

Dasuki, Hafidh, dkk., 1997, Ensiklopedi Islam, Jakarta: Ichtiar Baru Van Hoeve, cet. ke-2.

Ghazali, Abu Hamid al-, 1986, Ihya' Ulum al-Din, Surabaya: Hidayah.

Hasan, Abd al-Hakim, 1954, Al-Tashawwuf fi al-Syi'r al-'Arabi: Nasy'atuh wa Tathawwuruh hatta Akhir al-Qarn al-Tsalits al-Hijry, Kairo: Maktabah Angelo al-Misriyah.

Kalabadzi, Abu Bakar Muhammad Al-, 1960, Al-Ta'arruf li Madzhab Ahl alTashawwuf, Kairo: Dar al-Ma'rifah.

Khamis, Mohamad Atiyah, 1993, Penyair Wanita Sufi, Rabi'ah al-'Adawiyah, terj. Anas Mahyuddin, Jakarta: Pustaka Firdaus.

Mahmud, "Abd al-Qadir, 1946, Al-Falsafah al-Shufiyah fi al-Islam, Kairo: Dar al-Fikr al-'Arabi.

Makki, Abu Thalib al-, 1978, Qut al-Qulub fi Mu'amalat al-Mahbub, Beirut: Dar al-Fikr.

Mushthafa, Mohammad, 1945, Al-Hayah al-Ruhiyah fi al-Islam, Kairo: Dar alFikr al-'Arabi.

Nasr, Seyyed Hossein, 1994, Spiritualitas dan Seni Islam, terj. Sutejo, Bandung: Mizan. 
Nasution, Harun, 1989, Filsafat dan Misticisme dalam Islam, Jakarta: Bulan Bintang.

Qandil, Abd al-Mu'in, 1993, Figur Wanita Sufi, terj. M. Sofyan Amrullah, Pustaka Progressif:

Qusyairi, 'Abd al-Karim al-, 1982, Al-Risalah al-Qusyairiyah, Kairo, Dar alKhair.

Sakkakini, Widah el-, 1982, First among Sufis, the Life and Thoght of Rabi'a al- Adowiyya, terj. Nabil Safwat, London: Octagon Press.

Schimmel, Annemarie, 2000, Dimensi Mistik dalam Islam, terj. Sapardi Djoko Damono, Jakarta, Pustaka Firdaus.

..., 1997, My Soul is a Women, New York: H. Ray Continuum.

Sells, Michael A., 1996, Early Islamic Mysticism, New York: Paulist Press.

Smith, Margaret, 1997, Rabi'ah, Pergulatan Spiritual Perempuan, terj. Jamilah Baraja, Surabaya: Risalah Gusti.

Syu'aib bin 'Abd al-'Aziz al-Huraifisy, $104 \mathrm{H}$, Al-Raudl al-Fa'iq, Kairo: Dar. al-Ma'rifah.

Taftazani, Abu al-Wafa' al-Ghanimi al-, 1976, Madkhal ila al-Tashawwuf alIslami, Kairo: Dar al-Tsaqafah.

Thusi, Abu Nasr al- Sarraj al-, 1960, Al-Luma', Kairo: Dar al-Kutub alHaditsah.

Yafi' 'ie, Al-, 1324 H, Raudl al-Riyahin, Kairo: Dar al-Ma'rifah. 